\title{
Stage II Merkel Cell Carcinoma AJCC v7
}

National Cancer Institute

\section{Source}

National Cancer Institute. Stage II Merkel Cell Carcinoma A/CC v7. NCI Thesaurus. Code C85893.

Stage II includes: IIA: (T2/T3, pNO, M0), IIB: (T2/T3, cNO, M0), and IIC: (T4, N0, M0). T2:

Primary tumor greater than $2 \mathrm{~cm}$ but not more than $5 \mathrm{~cm}$ in maximum dimension. T3:

Primary tumor over $5 \mathrm{~cm}$ in maximum dimension. T4: Primary tumor invades bone, muscle, fascia, or cartilage. pN0: No regional lymph node metastasis by pathologic examination. cNO: No regional lymph node metastasis by clinical examination. N0: No regional lymph node metastasis. M0: No distant metastasis. (AJCC 7th Ed.) 